\title{
Education on Fall Prevention to Improve Self-Efficacy of Nursing Staff in Long Term Care: a Pilot Study
}

\author{
Mark D. Leverenz \\ Chatham University, mleverenz@icloud.com \\ Jennifer Lape \\ Chatham University, jlape@chatham.edu
}

Follow this and additional works at: https://nsuworks.nova.edu/ijahsp

Part of the Geriatric Nursing Commons, and the Occupational Therapy Commons

\section{Recommended Citation}

Leverenz MD, Lape J. Education on Fall Prevention to Improve Self-Efficacy of Nursing Staff in Long Term Care: a Pilot Study. The Internet Journal of Allied Health Sciences and Practice. 2018 Jan 01;16(3), Article 6.

This Manuscript is brought to you for free and open access by the College of Health Care Sciences at NSUWorks. It has been accepted for inclusion in Internet Journal of Allied Health Sciences and Practice by an authorized editor of NSUWorks. For more information, please contact nsuworks@nova.edu. 


\title{
Education on Fall Prevention to Improve Self-Efficacy of Nursing Staff in Long Term Care: a Pilot Study
}

\begin{abstract}
Purpose: Fall prevention is an ongoing concern in long-term care. Self-efficacy of nursing staff affects their performance levels related to fall prevention. Research concerning falls in the elderly is plentiful but there are no published studies addressing self-efficacy of nursing staff for implementation of fall prevention strategies in long-term care. The authors hypothesize that fall prevention education by an occupational therapist would be effective to improve the self-efficacy of nursing staff for implementation of fall prevention strategies and self-efficacy to prevent resident falls.

Method: A pre-test post-test pilot study implementing a five-week, multifaceted, fall prevention education course was conducted by an occupational therapist. The SEPF-A and SEPF-N were administered to the nursing staff respective of their professional licensure to assess falls self-efficacy before and after the course.

Results: Eight participants ( 6 certified nursing assistants \& 2 nurses) completed the course. A statistically significant improvement $(p=.043, a=.05)$ in falls self-efficacy was noted for the nursing assistants. Following training, there was a $40 \%$ increase in the SEPF-A and a $67 \%$ increase in the SEPF-N indicating an improvement in self-efficacy related to falls.

Conclusion: Fall prevention training by a licensed expert may be an effective approach to increase selfefficacy of nursing staff for implementation of fall prevention strategies and for prevention of resident falls in long-term care.
\end{abstract}

\section{Author Bio(s)}

Mark Leverenz OTD, OTR/L is the Director of Rehabilitation Services at Friendship Manor in Rock Island, IL. $\mathrm{He}$ is also an Adjunct Professor of Occupational Therapy at Chatham University in Pittsburgh, PA

Jennifer Lape OTD, OTR/L is an Assistant Professor of Occupational Therapy at Chatham University in Pittsburgh, PA. She is also co-author of Research for the Health Professional, a guide for research and evidence-based practice for a variety of healthcare students and professionals. 


\title{
TIAHSP" \\ The Internet Joưnal of Allied Health Sciences and Practice \\ Dedicated to allied health professional practice and education
}

Vol. 16 No. 3 ISSN 1540-580X

\section{Education on Fall Prevention to Improve Self-Efficacy of Nursing Staff in Long Term Care: A Pilot Study}

\author{
Mark D. Leverenz, OTD, OTR/L \\ Jennifer Lape, OTD, OTR/L \\ Chatham University \\ United States
}

\begin{abstract}
Purpose: Fall prevention is an ongoing concern in long-term care. Self-efficacy of nursing staff affects their performance levels related to fall prevention. Research concerning falls in the elderly is plentiful but there are no published studies addressing selfefficacy of nursing staff for implementation of fall prevention strategies in long-term care. The authors hypothesize that fall prevention education by an occupational therapist would be effective to improve the self-efficacy of nursing staff for implementation of fall prevention strategies and self-efficacy to prevent resident falls. Method: A pre-test post-test pilot study implementing a fiveweek, multifaceted, fall prevention education course was conducted by an occupational therapist. The Self-Efficacy for Preventing Falls-Assistant scale (SEPF-A) and the Self-Efficacy for Preventing Falls-Nurse (SEPF-N) scales were administered to the nursing staff respective of their professional licensure to assess falls self-efficacy before and after the course. Results: Eight participants (6 certified nursing assistants \& 2 nurses) completed the course. A statistically significant improvement in falls self-efficacy was noted for the nursing assistants $(p=0.0430)$. Following training, there was a $40 \%$ increase in the SEPF-A and a $67 \%$ increase in the SEPF-N indicating an improvement in self-efficacy related to falls. Conclusion: Fall prevention training by a licensed expert may be an effective approach to increase self-efficacy of nursing staff for implementation of fall prevention strategies and for prevention of resident falls in long-term care.
\end{abstract}

Key Words: fall prevention, self-efficacy, long-term care 


\section{INTRODUCTION}

The occurrence of falls in long-term care is higher than the rate for community dwelling individuals and possesses financial and psychological risks. Fall rates in long-term care settings are approximately three times that of elderly community dwellers, equating to rates of 1.5 falls per bed, per year (range 0.2 to 3.6). ${ }^{1}$ Falls of nursing home residents are associated with greater morbidity, mortality, and healthcare costs. ${ }^{2}$ These costs go beyond the financial concerns of health care because falls negatively affect resident functioning and are traumatic for residents, family members, and care providers. ${ }^{3}$ Falls are often caused by complex, contextually dependent, and interrelated factors occurring simultaneously, and no one approach is effective for treatment and prevention. ${ }^{1,4}$

Multiple studies contain evidence that multifaceted fall intervention programs, meaning those that employ a variety of strategies to address falls, significantly reduce the number of recurrent fallers and the incidence of falls among residents in settings caring for an elderly population. $14,5,5,6,7$ Existing studies that include or are generalizable to the long-term care setting discuss an array of strategies. A randomized control trial in an acute care hospital found targeting multiple interventions to specific patient risk factors was effective in reducing falls. ${ }^{5}$ Another study employed a multifactorial fall management program in two long-term care facilities and reported a significant decrease in falls that resulted in hospitalization. ${ }^{6} \mathrm{In}$ addition, a systematic review including 43 trials in long-term care facilities suggested possible benefits of multifaceted fall prevention approaches but the results did not indicate one combination of approaches to be effective in all scenarios. ${ }^{7}$ Cameron et al. concluded that targeting multiple risk factors may be effective in decreasing fall rates. ${ }^{7}$ The lack of consensus in some studies is related to the complex nature of falls including dynamic resident, environmental, and contextual factors. ${ }^{7}$

Despite the absence of a standard approach to treatment and prevention of falls, multiple studies on fall prevention support

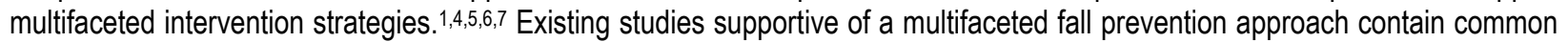
elements that include, but are not limited to, use of an educational component, considerations of staff and caregiver self-efficacy, strength and balance interventions, environmental modifications, appropriate use of mobility aides, visual screenings, and attentiveness to the conflict between resident safety and mobility. $4,5 \mathrm{At}$ the center of preventing falls is the issue of mobility. Mobility preserves functional capability and helps the elderly maintain independence while decreasing fall risk. ${ }^{8}$ The negative effect of immobility on multiple body systems is documented and directly relates to balance and fall risk. ${ }^{9}$ Despite research in support of mobility promotion, there often exists tension between resident safety and mobility optimization. ${ }^{10}$ Some approaches designed to prevent falls, such as limiting ambulation and accepting sitting as the default resident position, may be more detrimental to the resident than a possible fall. ${ }^{1}$

Fall prevention education for resident-care stakeholders by a fall prevention expert is another component that is supported in the literature. A fall prevention expert is someone who has knowledge, obtained through a combination of education, training, and experience, to address the problem of falls. A systematic review of five randomized control trials in long-term care facilities concluded that fall prevention programming involving education of staff, environmental modifications, medication review, maintenance of mobility aides, and exercise programs reduced falls. ${ }^{4} \mathrm{Ang}$ et al concluded that education by specialist research nurses reduced falls in a hospital setting. ${ }^{5}$ Additional research emphasized the specialist's role of a physical therapist for educating staff on mobility optimization, which is an important component of fall prevention. ${ }^{10}$ Though evidence supports education as a facet of fall prevention, the component of self-efficacy may also be helpful in moving from education to practice.

Self-efficacy refers to the "belief in one's capability to carry out actions necessary to meet given situational demands," ${ }^{3}$ and this affective dimension is a key component in actually implementing practices that have been taught. 3,11,12 Self-efficacy is also correlated with desirable performance characteristics such as goal directed, motivational, and problem solving behaviors, and improved self-efficacy results in sustained positive behavior change..$^{11,12}$ Institutionally, self-efficacy is important to long-term care organizations because the performance of individual caregivers is linked to the overall performance of their facilities. ${ }^{3}$ Of the multiple components of fall prevention strategies mentioned in the literature, self-efficacy holds potential to effect all others because selfefficacy of staff is related to positive behaviors, including actively employing a variety of strategies to prevent falls. 11,12,13

In this pilot study, the authors hypothesized that structured fall prevention education provided by an occupational therapist with expertise in fall prevention for the elderly population would improve self-efficacy of nursing staff for implementation of fall prevention strategies that promote decreased resident falls. In this article, the use of "nursing staff" includes registered nurses (RN), licensed practical nurses (LPN), and certified nursing assistants (CNA), while recognizing the significant differences in the education and work role of these forms of nursing personnel. An occupational therapy perspective was specifically chosen for the foundation of this study as the traditional role of occupational therapy in the skilled nursing setting is one of direct intervention with residents, which limits the impact of intervention to the resident-therapist relationship. However, educating nursing staff on strategies to more effectively address falls in the residents could broaden the impact of occupational therapy related to falls prevention. No known

(c) The Internet Journal of Allied Health Sciences and Practice, 2018 
study to-date has focused on improving self-efficacy of nursing staff through education by a fall prevention expert in the long-term care setting; therefore, the purpose of this pilot study was to apply literature on multifaceted fall prevention strategies guided by an occupational therapy frame of reference, to the design and implementation a multifaceted fall prevention educational program for a sample of nursing staff in one long-term care facility to determine the impact on the staff's self-efficacy.

\section{METHODS \\ Study Design}

The pre-test post-test pilot study was conducted by an experienced occupational therapist, at a long-term care facility in the state of Illinois, USA. The study included eight nursing staff members from the rehabilitation unit who enrolled in a 5-week fall prevention education program. Attendance was a mandatory requirement of employment, but participation in the pre- and postintervention surveys was voluntary. The study was approved by Chatham University's Institutional Review Board, and each participant signed an informed consent document.

\section{Participants}

Eight nursing staff members, recruited through convenience sampling, were identified for participation in the fall prevention education course, which occurred over a five-week implementation period. All eight individuals met the inclusion criteria of being full-time nursing staff employed at the long-term care facility whose primary work assignment was first shift on the rehabilitation unit. The sample of nursing staff consisted of six CNAs, one LPN, and one RN. They were informed that participating in the surveys and allowing analysis of the data was optional. Table 1 further summarizes the participant demographics.

Table 1.Participant Profiles

\begin{tabular}{|l|l|l|l|l|}
\hline $\begin{array}{l}\text { Nursing Staff } \\
\text { Identification\# }\end{array}$ & Gender & $\begin{array}{l}\text { Age Range } \\
\text { (years) }\end{array}$ & Nursing License & Years Working \\
\hline 1 & Female & $18-24$ & $\begin{array}{l}\text { Certified Nursing } \\
\text { Assistant }\end{array}$ & $1-5$ \\
\hline 2 & Female & $25-34$ & $\begin{array}{l}\text { Certified Nursing } \\
\text { Assistant }\end{array}$ & $6-10$ \\
\hline 3 & Female & $18-24$ & $\begin{array}{l}\text { Certified Nursing } \\
\text { Assistant }\end{array}$ & $<1$ \\
\hline 4 & Female & $18-24$ & $\begin{array}{l}\text { Certified Nursing } \\
\text { Assistant }\end{array}$ & $6-10$ \\
\hline 5 & Female & $25-34$ & $\begin{array}{l}\text { Certified Nursing } \\
\text { Assistant }\end{array}$ & $11-15$ \\
\hline 6 & Female & $18-24$ & $\begin{array}{l}\text { Certified Nursing } \\
\text { Assistant }\end{array}$ & $1-5$ \\
\hline 7 & Female & $35-44$ & Registered Nurse & $6-10$ \\
\hline 8 & Female & $55-64$ & $\begin{array}{l}\text { Licensed Practical } \\
\text { Nurse }\end{array}$ & $21+$ \\
\hline
\end{tabular}

\section{Outcome Measures}

Author permission was obtained for use of the 8-item Self-Efficacy for Preventing Falls-Assistant scale (SEPF-A) and the 11item Self-Efficacy for Preventing Falls-Nurse (SEPF-N) scale. These scales, which were administered before and after the fall prevention education course, asked the nursing staff to rate their confidence in their ability to prevent residents from falling as related to each scale item. The SEPF-N was administered to licensed practical nurse and registered nurse participants. The SEPF-A was administered to the certified nursing assistant participants. To reduce the risk of bias, administration of the scales was performed by a facility staff member not affiliated with the study and the scales were labeled by numeric identifiers rather than participant names.

The scales have demonstrated validity and reliability relative to individual items and scale totals in assessment of nursing staff's self-efficacy beliefs for preventing falls. ${ }^{3}$ Though these scales were originally tested in a hospital setting, there are similarities between the hospital and long-term care environments. In both settings, nursing staff care for patients with multiple medical conditions who are at risk for falls. ${ }^{3}$ 
A post-training survey, designed by the first author, was used to obtain demographic information from the nursing staff, assess satisfaction with the training, measure the collaborative nature of the training, and gather additional self-efficacy data. A section was included to elicit qualitative feedback related to the strengths and weaknesses of the individual and group training sessions. Group averages for the survey items were calculated to determine perceived effectiveness of the trainings and guide improvements for future trainings. Pilot testing, feedback from professionals familiar with the elements of quality survey design, use of standard language rules, and definition of terms were employed to address reliability and validity during design of the survey. ${ }^{14}$ Unlike the SEPF scales, this survey did not distinguish between professional licensure of the nursing personnel and all participants completed this same survey. Finally, the occupational therapist educator recorded field notes during the group training sessions to document evidence-based fall prevention implementation ideas that arose during group discussion.

\section{Intervention}

The intervention design was based on a multifaceted approach to fall prevention as supported in the literature. ${ }^{5,7}$ The theme of mobility promotion was integrated into the training because there is a link between mobility and occupational health of the residents. ${ }^{15}$ An environment of mutual participation was facilitated throughout the training, which consisted of group education sessions followed by individual sessions on the same day. Both group and individual training sessions were conducted by the same occupational therapist (first author).

Group education sessions consisted of six learning modules, each with a different fall prevention content area relevant to longterm care. After the initial group session, each subsequent group session began with a review of the previous learning module. Acronyms, alliteration, visual representations, and experiential learning activities were used to facilitate knowledge and comprehension of core concepts in preparation for implementing the fall prevention strategies. The learning modules were made readily accessible to the nurses in notebook form and in digital format upon request.

The individual training sessions were completed after each of the weekly group sessions and on the same day. These sessions were one-to-one collaborations between each nursing staff member and the occupational therapist during normal resident-care time. The nursing staff members were instructed to identify a need for fall prevention strategies from the group session and apply the strategies. The occupational therapist encouraged dialogue about the fall prevention strategies as related to the immediate resident-care context. Written feedback was provided to each nursing staff member after every individual training session through an informal written feedback form. Feedback consisted of communication to the nursing staff regarding their ability to identify and implement the various fall prevention strategies. The training sequence of group sessions followed by individual sessions, use of verbal feedback, and use of written feedback, were selected because feedback and its timing is a critical component in facilitating a desired level of performance. ${ }^{16}$ Table 2 includes a summary of the training sessions.

\begin{tabular}{|c|c|c|c|c|}
\hline Week & Content Area & Materials & Group Education & $\begin{array}{l}\text { Individual } \\
\text { Education }\end{array}$ \\
\hline 1 & $\begin{array}{l}\text { Visual } \\
\text { Considerations }\end{array}$ & $\begin{array}{l}\text { Prezi presentation, paper for } \\
\text { note taking, \& Individual } \\
\text { Education Feedback Form }\end{array}$ & $\begin{array}{l}\text { 30-Minute Prezi } \\
\text { Presentation }\end{array}$ & $\begin{array}{l}\text { Resident/Nursing } \\
\text { Staff Interactions- } \\
30 \text { Minutes }\end{array}$ \\
\hline 2 & Assistive Devices & $\begin{array}{l}\text { PowerPoint presentation, paper } \\
\text { for note taking, \& Individual } \\
\text { Education Feedback Form }\end{array}$ & $\begin{array}{l}\text { 30-Minute } \\
\text { PowerPoint } \\
\text { Presentation }\end{array}$ & $\begin{array}{l}\text { Resident/Nursing } \\
\text { Staff Interactions- } \\
30 \text { Minutes }\end{array}$ \\
\hline 3 & $\begin{array}{l}\text { Environmental } \\
\text { Considerations }\end{array}$ & $\begin{array}{l}\text { PowerPoint presentation, paper } \\
\text { for note taking, \& Individual } \\
\text { Education Feedback Form }\end{array}$ & $\begin{array}{l}\text { 30-Minute } \\
\text { PowerPoint } \\
\text { Presentation }\end{array}$ & $\begin{array}{l}\text { Resident/Nursing } \\
\text { Staff Interactions- } \\
30 \text { Minutes }\end{array}$ \\
\hline 4 & $\begin{array}{l}\text { Pressure and Motion } \\
\text { Alarms }\end{array}$ & $\begin{array}{l}\text { PowerPoint presentation, paper } \\
\text { for note taking, \& Individual } \\
\text { Education Feedback Form }\end{array}$ & $\begin{array}{l}\text { 30-Minute } \\
\text { PowerPoint } \\
\text { Presentation }\end{array}$ & $\begin{array}{l}\text { Resident/Nursing } \\
\text { Staff Interactions- } \\
30 \text { Minutes }\end{array}$ \\
\hline 5 & Mobility & $\begin{array}{l}\text { PowerPoint presentation, paper } \\
\text { for note taking, \& Individual } \\
\text { Education Feedback Form }\end{array}$ & $\begin{array}{l}\text { 30-Minute } \\
\text { PowerPoint } \\
\text { Presentation }\end{array}$ & $\begin{array}{l}\text { Resident/Nursing } \\
\text { Staff Interactions- } \\
30 \text { Minutes }\end{array}$ \\
\hline 6 & $\begin{array}{l}\text { Therapeutic Use-of- } \\
\text { Self }\end{array}$ & $\begin{array}{l}\text { PowerPoint presentation, paper } \\
\text { for note taking, \& Individual } \\
\text { Education Feedback Form }\end{array}$ & $\begin{array}{l}\text { 30-Minute } \\
\text { PowerPoint } \\
\text { Presentation }\end{array}$ & $\begin{array}{l}\text { Resident/Nursing } \\
\text { Staff Interactions- } \\
30 \text { Minutes }\end{array}$ \\
\hline
\end{tabular}

(c) The Internet Journal of Allied Health Sciences and Practice, 2018 


\section{Data Analysis}

Data obtained from the pre- and post-SEPF-A scales were analyzed with inferential statistics using the SPSS Statistics software package (Version 25; IBM Corporation); a limited sample of only 2 nurse participants (one LPN and one RN) prevented inferential analysis of the pre- and post-SEPF-N scale data. Descriptive statistical methods were also used to analyze the data from the SEPF-A and SEPF-N, which were administered before and after the training. The mean scores for the SEPF-A and SEPF-N were calculated by summing the scores from each participant and dividing by the total number of participants completing each assessment. Bar graphs (see Figures $1 \& 2$ ) are provided for visual comparison. The percentage of change was also calculated for several assessment items from the SEPF-A and SEPF-N believed to represent the greatest deficit areas based upon observation and experience in the skilled nursing facility (See Table 3). Last, the occupational therapist's field notes were examined to extract fall prevention strategies generated during the group trainings (Tables $4 \& 5$ ).

\section{RESULTS}

A non-parametric related-samples Wilcoxon signed-rank test showed that a five-week, multifaceted, fall prevention education course elicited a statistically significant improvement $(p=0.043, \square<.05)$ in the self-efficacy for preventing falls in the certified nursing assistant participants. While improvements were also noted in the falls self-efficacy of the nursing participants, inferential analysis was impractical due to the small number of participants in this category $(n=2)$. Descriptively, cumulate scale totals for both groups of participants suggests an increase in self-efficacy after the fall prevention trainings. Figures 1 and 2 depict the cumulate average of pre-training versus post-training scores representing a $40 \%$ increase on the SEPF-A scale and a $67 \%$ increase on the SEPF-N scale. SEPF-A pre-training cumulate average scores ranged from 19 to 24 , and post- training cumulate average range from 34 to 48 . SEPF-N pre-training cumulate average scores ranged from 18 to 48 with the post training range from 31 to 48 .

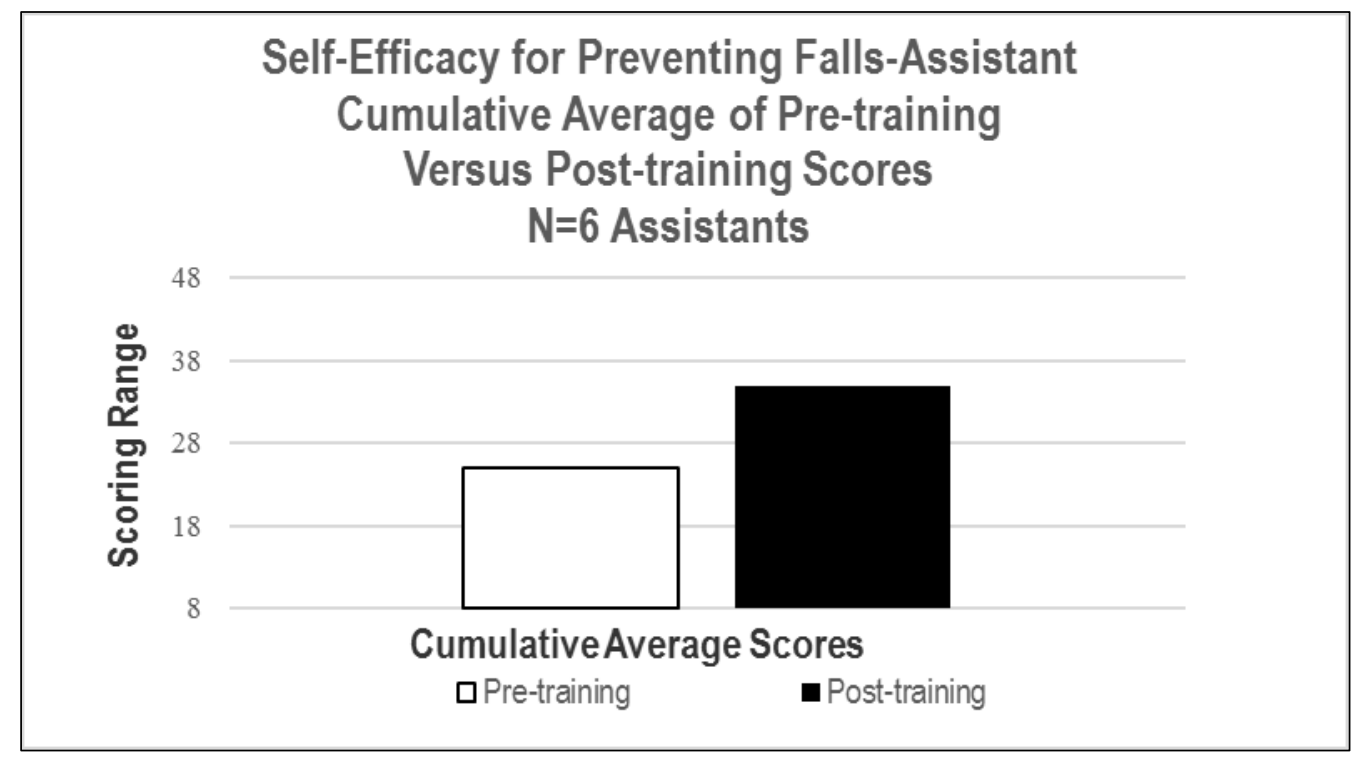

Figure 1. Self-Efficacy for Preventing Falls-Assistant Cumulative Average of Pre-training Versus Post-training Scores 


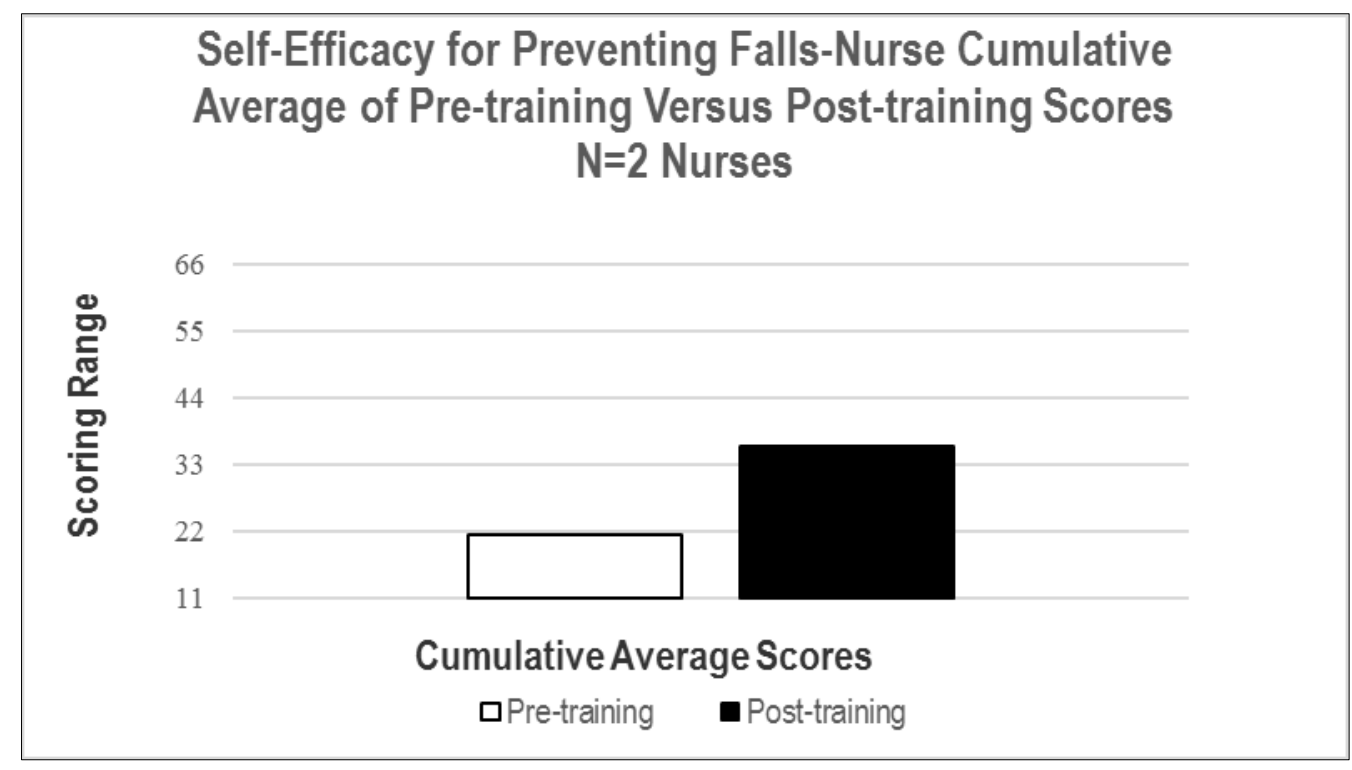

Figure 2. Self-Efficacy for Preventing Falls-Nurse Cumulative Average of Pre-training Versus Post-training Scores

Table 3. Self-Efficacy for Preventing Falls Individual Scale Items Post-Training Change

\begin{tabular}{|l|l|l|l|}
\hline Self-Efficacy for Preventing Falls & Individual Scale Items Post-Training Change \\
\hline Scale & Item\# & Item Statement & $\begin{array}{l}62 \% \\
\text { Increase }\end{array}$ \\
\hline SEPF-A & 1 & I receive a verbal report about my patients' fall risk. & $\begin{array}{l}57 \% \\
\text { Increase }\end{array}$ \\
\hline SEPF-A & 8 & We all work together as a team. & $\begin{array}{l}200 \% \\
\text { Increase }\end{array}$ \\
\hline SEPF-N & 3 & I have easy access to information about why patients are at risk to fall. & $\begin{array}{l}133 \% \\
\text { Increase }\end{array}$ \\
\hline SEPF-N & 7 & I give nursing assistants face-to-face report about their patient's fall risk. & $\begin{array}{l}133 \% \\
\text { Increase }\end{array}$ \\
\hline SEPF-N & 8 & $\begin{array}{l}\text { I give nursing assistants face-to-face information about how to prevent their patients } \\
\text { from falling }\end{array}$ & \\
\hline $\begin{array}{l}\text { Notes. SEPF-A/N = Self-Efficacy for Preventing Falls-Assistant/Nurse Scale. } \\
\text { a Pre-test average group score divided by post-test average group score. }\end{array}$
\end{tabular}

For self-efficacy beliefs, $63 \%$ of the nursing staff reported being extremely confident to implement strategies from the training sessions and $75 \%$ responded as somewhat confident to prevent resident falls. On a survey item designed to measure the collaborative manner of the training, $75 \%$ of nursing staff strongly agreed that their active participation and feedback was welcomed and encouraged. Seventy-five percent of nursing staff reported extreme satisfaction with the group training sessions. Less satisfaction was reported with individual training sessions as $63 \%$ of nursing staff provided a neutral response on the related survey item. There were no definitive themes identified in the qualitative responses.

A client-centered approach was used by the occupational therapist which included allowance of ample time for questions, responses, and spontaneous interaction among the group. This environment fostered generation of ideas from the nursing staff, as summarized in Table 4, in preparation for implementing evidence-based fall prevention strategies within their resident-care contexts. 
Table 4. Group Training Session Profiles

\begin{tabular}{|c|c|c|c|c|c|}
\hline $\begin{array}{l}\text { Week \# } \\
\text { \&Topic }\end{array}$ & Session Time & Attendance & Learning Activities & $\begin{array}{l}\text { Implementation } \\
\text { Ideas }\end{array}$ & $\begin{array}{l}\text { Actively } \\
\text { Participating } \\
\text { Nursing Staff }\end{array}$ \\
\hline $\begin{array}{l}1- \\
\text { Visual } \\
\text { Considerations }\end{array}$ & 65 minutes & $8 / 8$ & $\begin{array}{l}\text { > Balance challenge } \\
\text { > Visual impairments } \\
\text { quiz }\end{array}$ & $\begin{array}{l}>\text { Label glasses } \\
>\text { Visiting } \\
\text { optometrist } \\
>\text { Transition } \\
\text { highlighting } \\
\text { strategies }\end{array}$ & $6 / 8$ \\
\hline $\begin{array}{l}\text { 2- } \\
\text { Assistive Devices }\end{array}$ & 50 minutes & $7 / 8$ & $\begin{array}{l}\text { D Review quiz } \\
\text { > Adjusting Assistive } \\
\text { Devices } \\
\text { > Knowledge quiz }\end{array}$ & $\begin{array}{l}\text { > Repair tracking } \\
\text { > Labeling } \\
\text { strategies } \\
\text { >In-service on } \\
\text { assist levels } \\
\text { binder }\end{array}$ & $7 / 8$ \\
\hline $\begin{array}{l}\text { 3- } \\
\text { Environment }\end{array}$ & 45 minutes & $8 / 8$ & $\begin{array}{l}>\text { Review quiz } \\
>\text { Knowledge quiz }\end{array}$ & $\begin{array}{l}>\text { Improve } \\
\text { roommate pairing } \\
\text { to reduce clutter }\end{array}$ & $7 / 8$ \\
\hline $\begin{array}{l}4- \\
\text { Alarms }\end{array}$ & 45 minutes & $7 / 8$ & $\begin{array}{l}\text { > Review quiz } \\
\text { > Practice proper } \\
\text { alarm application } \\
>\text { Knowledge quiz }\end{array}$ & $\begin{array}{l}>\text { Battery check } \\
\text { schedule } \\
>\text { Consult therapy }\end{array}$ & $7 / 8$ \\
\hline $\begin{array}{l}5.1- \\
\text { Mobility }\end{array}$ & 45 minutes & $8 / 8$ & $\begin{array}{l}>\text { Review quiz } \\
>\text { Knowledge quiz }\end{array}$ & $\begin{array}{l}>\text { Do not fear } \\
\text { resident mobility } \\
>\text { Consult therapy }\end{array}$ & $7 / 8$ \\
\hline $\begin{array}{l}{ }^{*} \text { 5.2-Therapuetic } \\
\text { Use of Self }\end{array}$ & 30 minutes & $8 / 8$ & $\begin{array}{l}>\text { Review quiz } \\
>\text { Knowledge quiz }\end{array}$ & $\begin{array}{l}>\text { Be conscious of } \\
\text { use of self }\end{array}$ & $7 / 8$ \\
\hline
\end{tabular}

*Note: Topics 5.1 and 5.2 were presented on the same day due to an unforeseen scheduling conflict.

During individual training sessions, thought provoking questions were used to facilitate independent thinking about application of the strategies. On average, nursing staff members identified two to three appropriate strategies for implementation with their residents as summarized in Table 5.

Table 5. Individual Training Session Profiles

\begin{tabular}{|l|l|l|l|l|}
\hline \multicolumn{1}{|c|}{$\begin{array}{l}\text { Week \# } \\
\text { \& Topic }\end{array}$} & \multicolumn{1}{|c|}{$\begin{array}{c}\text { Average } \\
\text { Session } \\
\text { Time }\end{array}$} & \multicolumn{1}{|c|}{ Attendance } & \multicolumn{1}{c|}{$\begin{array}{c}\text { Average \# of } \\
\text { Strategies Identified }\end{array}$} & \multicolumn{1}{c|}{$\begin{array}{c}\text { Average \# of } \\
\text { Strategies } \\
\text { Unidentified }\end{array}$} \\
\hline $\begin{array}{l}1- \\
\text { Visual Considerations }\end{array}$ & $\begin{array}{l}\text { Two,10- } \\
\text { minute sessions }\end{array}$ & $100 \%$ & 3 & 1 \\
\hline $\begin{array}{l}2- \\
\text { Assistive Devices }\end{array}$ & $\begin{array}{l}\text { Two,10-minute } \\
\text { sessions }\end{array}$ & $100 \%$ & 3 & 1 \\
\hline $\begin{array}{l}3- \\
\text { Environment }\end{array}$ & $\begin{array}{l}\text { Two,10-minute } \\
\text { sessions }\end{array}$ & $100 \%$ & 2.75 & 1 \\
\hline $\begin{array}{l}4- \\
\text { Alarms }\end{array}$ & $\begin{array}{l}\text { Two,10-minute } \\
\text { sessions }\end{array}$ & $100 \%$ & 3 & 2 \\
\hline $\begin{array}{l}5.1- \\
\text { Mobility }\end{array}$ & $\begin{array}{l}\text { One, 20 minute } \\
\text { session }\end{array}$ & $100 \%$ & 3 & 2 \\
\hline $\begin{array}{l}5.2- \\
\text { Therapeutic } \\
\text { Use of Self }\end{array}$ & $\begin{array}{l}\text { One, 10-minute } \\
\text { session }\end{array}$ & $100 \%$ & 2 & \\
\hline
\end{tabular}




\section{DISCUSSION}

Outcomes of this pilot study are consistent with findings in current research. Fall prevention strategies that are multifaceted, include an educational component, and consider staff self-efficacy were the primary considerations for this intervention. ${ }^{4,5,10,11,12} \mathrm{Additional}$ considerations included the conflict between mobility promotion and safety, a collaborative approach to program implementation, and the nursing staff's satisfaction with the training. ${ }^{6,17}$

\section{Multifaceted Approach to Fall Prevention}

The preponderance of evidence for use of a multifaceted approach guided the trainings in this study. The study used a multifaceted approach by training nurses on six different fall prevention content areas and corresponding strategies tailored to the long-term care setting (Tables $2 \& 4$ ). Consistent with the literature, the results of using a multifaceted approach to fall prevention in this study yielded desirable outcomes related to self-efficacy, collaboration, and satisfaction with the trainings.

\section{Educational Component of Fall Prevention}

The group training sessions successfully aided the nursing staff in remembering and understanding the presented information. This was evident in the individual education sessions where each nursing staff member demonstrated the ability to apply concepts from each topic into her resident-care contexts. The measured increases in self-efficacy related to fall prevention are attributed to the educational component of the pilot study (Figures $1 \& 2$ ). An increase in self-efficacy related to accessing information about why residents are at risk to fall, and how to prevent them from falling, also reflects upon the educational component of the study (Table 3). It is logical to link the increases in self-efficacy to the educational component because education was the primary activity occurring throughout the fall prevention training.

\section{Self-efficacy Component of Fall Prevention}

In this study, nursing staff's self-efficacy improved as measured by the pre and post-test total scale scores of the SEPF scales (Figures $1 \& 2$ ). Self-efficacy data was also gathered through the post-training survey. This survey indicated $78 \%$ of the nursing staff were extremely or somewhat confident to implement the fall prevention strategies on which they were trained. The same survey reported $75 \%$ of the nursing staff were somewhat confident to prevent resident falls. These results are clinically significant because self-efficacy is linked to the performance of individual caregivers, which affects the overall performance of a facility. ${ }^{3}$

The self-efficacy data was consistently positive. However, less self-efficacy was reported for preventing resident falls than for implementing fall prevention strategies. The scope of the five-week study allowed minimal time for integration of the fall prevention strategies into clinical practice, which could have contributed to this discrepancy.

\section{Collaboration and Fall Prevention}

Seventy-five percent of the nursing staff strongly agreed that their active participation and feedback was welcomed and encouraged during the training, suggesting it was implemented in a collaborative manner. Occupational therapists work in a spirit of mutual participation with their clients, an approach that was taken with the nursing staff throughout this study. ${ }^{15}$ Literature confirms that a collaborative and multidisciplinary approach to fall prevention is necessary because of the complex nature of falls. 6,10

\section{Mobility and Fall Prevention}

At the center of preventing falls is the issue of mobility. Mobility-promoting fall prevention strategies were embraced by the nursing staff as noted through some of their qualitative feedback. One nursing staff member stated, "Mobility was a strength of the group training sessions." The interconnectedness between resident occupation, tasks that are purposeful and meaningful to the individual, and resident mobility prompted the occupational therapist to weave a theme of mobility promotion throughout the fall prevention training. ${ }^{15}$

\section{Fall Prevention Training Satisfaction}

High satisfaction levels were reported for the group training sessions with three nursing staff members stating the group format was a strength of the training. Significantly less satisfaction was reported with the individual training sessions. This difference is attributed to the periodic difficulty of the nursing staff to simultaneously attend to the individual training activity and resident-care responsibilities.

\section{Recommendations for Practice and Future Research}

The outcomes of this study support use of evidence-based fall prevention training by a credible expert for long-term care nursing staff with some recommended modifications. The individual training sessions scored a neutral satisfaction rating by the nursing staff. Implementing the individual trainings when nursing staff members do not have resident-care responsibilities or lessening their 
responsibilities for training is recommended. This would eliminate the burden of attending to residents and the individual training activities concurrently.

The nursing staff reported confidence in implementing the fall prevention strategies but less confidence in preventing resident falls. A post-study follow-up survey could help determine if additional time for strategy implementation could further impact self-efficacy to prevent resident falls. Posting periodic reports on facility fall rates could also provide feedback associating the fall prevention strategies and their effects on residents. This feedback may improve the nursing staff's confidence to reduce resident falls and reinforce implementation of the evidence-based fall prevention strategies. Further studies exploring nursing staff's self-efficacy and resident fall rates in long-term care are needed to determine the relationship between these two variables.

The outcomes of this study create an additional clinical question: Will the nursing staff's improved self-efficacy result in a reduction in the number of resident falls? The fall prevention training had a positive effect on the nursing staff's self-efficacy, but the scope of the study did not allow for consideration of resident outcomes. Research incorporating the evidence-based training of this pilot study while exploring the relationship between self-efficacy and resident falls is recommended. Evidence connecting nursing staff's self-efficacy and resident fall rates in long-term care would be a significant contribution to the fall prevention literature and a logical follow-up to this study.

The qualitative data was limited by the small sample size and timing of the final survey. The qualitative items were the last section of the final survey administered at the end of the nursing staff's shift, which may have contributed to the lack of detail in their responses. A follow-up study with a larger sample of nurses is recommended to improve external validity and allow for generalization of results. In future studies, a more optimal time to administer post-training surveys should be contemplated. Separating nursing staff by their educational backgrounds should also be considered to better tailor education to specific roles within the nursing profession.

\section{SUMMARY}

Despite extensive research on fall prevention, there is no known work combining all components of this pilot study. An occupational therapy frame of reference, and literature supportive of the fall prevention content areas guided the design and implementation of the study. The study was also grounded in an evidence-based approach by integrating the occupational therapist's clinical expertise with external evidence, while considering the nursing staff as mutual contributors throughout the training process.

Self-efficacy is important to measure because it has influence on desirable behaviors. Outcomes of this study suggest that training by a credible expert for long-term care nursing staff can improve their self-efficacy to implement fall prevention strategies. Further research is needed to determine if improved self-efficacy of nursing staff related to fall prevention ultimately leads to a reduction in resident falls.

\section{REFERENCES}

1. Rubenstein L, Josephson K, Robbins A. Falls in the nursing home. Ann Intern Med. 1994;121(6):442-451.

2. Leland N, Gozalo P, Teno J, Mor V. Falls in newly admitted nursing home residents: A national study. J Am Geriatr Soc. 2012;60(5). doi:10.1111/j.1532-5415.2012.03931.x

3. Dykes P, Carroll D, McColgan K, et al. Scales for assessing self-efficacy of nurses and assistants for preventing falls. J Adv Nurs. 2011;67(2):438-449. doi:10.1111/j.1365-2648.2010.05501.x

4. Cusimano M, Kwok J, Spadafora K. Effectiveness of multifaceted fall-prevention programs for the elderly in residential care. Inj Prev. 2008;14:113-122. doi:10.1136/ip.2007.017533

5. Ang E, Mordiffi S, Wong $\mathrm{H}$. Evaluating the use of a targeted multiple intervention strategy in reducing patient falls in an acute care hospital: A randomized controlled trial. J Adv Nurs. 2011;67(9):1984-1992.

6. Burland $E$, Martens $P$, Brownell $M$, Doupe $M$, Fuchs $D$. The evaluation of a fall management program in a nursing home population. Gerontologist. 2013;53(5):828-838. doi:10.1093/geront/gns197

7. Cameron I, Gillespie L, Robertson M, et al. Interventions for preventing falls in older people in care facilities and hospitals. Cochrane Database Syst Rev. 2012(12):1-181. doi:10.1002/14651858.CD005465.pub3

8. Vago P, Lovecchio N. Morphological and functional modifications during the process of ageing: Characteristics and benefits of physical activity. Annales Kinesiologiae. 2014;5(1):3-14.

9. Mahoney J. Immobility and falls. Clin Geriatr Med. 1998;14(4):699-726.

(c) The Internet Journal of Allied Health Sciences and Practice, 2018 
10. Taylor J, Sims J, Haines TP. The influence of protection, palliation and costs on mobility optimization of residents in nursing homes: A thematic analysis of discourse. Int J Nurs Stud. 2012;49:1364-1374.

11. Kalkan M, Odacı H, Koç HE. Self-efficacy, coping with stress and goal-orientation in nurse managers. Cypriot Journal of Educational Sciences. 2011;3:118-125.

12. Nørgaard B, Ammentorp J, Kofoed P. Long term follow-up on health care professionals' self-efficacy after communication skills training. J Nurs Educ Pract. 2013;3(10):91-98. doi:10.5430/jnep.v3n10p91

13. Johnson S, Ostaszkiewicz J, O'Connell B. Moving beyond resistance to restraint minimization: A case study of change management in aged care. Worldviews Evid Based Nurs. 2009;6(4):210-218.

14. Fink A. How to Conduct Surveys: A Step-By-Step Guide. 5th ed. Thousand Oaks, CA: SAGE Publications; 2012.

15. American Occupational Therapy Association. Occupational therapy practice framework: Domain and process (3rd ed.). Am Journal Occup Ther. 2014;68(Suppl. 1):S1-S48. doi:10.5014/ajot.2014.682006

16. Ambrose S, Bridges M, DiPietro M, Lovett M, Norman M. How Learning Works: Seven Research-Based Principles for Smart Teaching. San Francisco, CA: Wiley Publishing; 2010.

17. Wu S, Wu S, Huang H. Nurses' attitudes towards physical activity care among older people. J Clin Nurs. 2012;22:1653-1662. doi:10.1111/j.1365-2702.2012.04260.x 